\title{
DEVELOPMENT
}

\section{Scope of DSD-linked conditions shown}

Disorders of sex development (DSD), a heterogeneous group of rare genetic conditions, are characterized by reproductive anomalies. Around onequarter of affected individuals could also harbour additional developmental defects not affecting the genitalia, a study finds.

The researchers surveyed data on diagnosis, genetic investigations, sex of rearing and associated anomalies of 649 patients with DSD enrolled in an international online registry (I-DSD). "Other studies have been performed in this area but never to this scale," explains lead researcher Faisal Ahmed, a paediatric endocrinologist at the University of Glasgow. “This work was only possible because of the I-DSD registry, which represents an example of how professionals can cross geographical boundaries and work together in the field of rare diseases," he adds.

Associated developmental conditions mainly affected growth, the heart and the central nervous system among
$\mathrm{XY}$ cases of DSD, whereas XX cases were characterized by skeletal and kidney defects. Linked abnormalities among males with 45,X/46,XY mixed gonadal dysgenesis were more frequent than previously thought. The presence of androgen-receptor mutations among patients presenting with androgen insensitivity disorder and associated abnormalities raises the possibility that this protein might have a wide developmental role.

"A better knowledge of the range of problems in people with DSD raises clinical awareness of these other abnormalities," Ahmed notes, "so doctors can think of the whole person rather than simply the problems associated with sex development."

\section{Vicky Heath}

Original article Cox, K. et al. Novel associations in disorders of sex development: findings from the I-DSD registry. J. Clin. Endocrinol. Metab. doi:10.1210/ jc.2013-2918 